\title{
Diversity across the Curriculum: Perceptions and Practices
}

\author{
Heather Wyatt-Nichol \\ Kwame Badu Antwi-Boasiako \\ Stephen F. Austin State University
}

\begin{abstract}
One step toward generating social equity in public policy and administration is to expose future leaders within the field to a variety of discourses from historically marginalized groups. The new Diversity Across the Curriculum standard recently passed by NASPAA requires MPA/MPP programs to incorporate diversity into the curriculum and other program activities. Through the use of a survey of program directors and a separate content analysis, this study examined the extent to which stand-alone courses on diversity are offered, the instructional strategies used to incorporate the subject of diversity into existing courses, and MPA/MPP program directors' perception of the standard. Results indicate that race, ethnicity, and gender continue to receive more attention than other elements of diversity. Most programs also attempt to integrate issues of diversity into existing courses rather than offer stand-alone courses. Program directors emphasized the need for flexibility because of variations in size, composition, and resources of graduate public policy and administration programs.
\end{abstract}

The concern for diversity continues to grow in salience within the public and private sectors. It is often stated that diversity means different things to different people. Although there are variations in the definitions of diversity, the term is generally defined as "race, ethnicity, class, gender, sexual orientation, age, religion, and disability differences among people” (White, 2004, 115). In comparison, cultural competence has been defined as the ability to effectively interact with individuals different from oneself (Rice, 2004; Rubaii-Barrett, 2006; White, 2004). Cultural competence is essential in today's society. Our population is becoming more diverse. Gribbin and McCain (1999) found that the minority population in America has doubled since the 1950s and contended that approxi- 
mately 120 million people will be added to the current American population by 2050, with ethnic and racial minorities possibly comprising more than 90 percent of these new Americans. Although their conclusion was based on statistical prediction using population figures, it provides statistical probability of how we as a society must prepare for diversity. Such projections allow public administrators to plan ahead to prepare for meeting the demands and expectations of both employees and constituents.

Our workforce has also become more diverse. The labor force participation rate of women is 59 percent (Bureau of Labor Statistics, 2005). African Americans comprise 11 percent of the labor force, Hispanic and Latinos account for 14 percent, and Asians represent 4 percent (Bureau of Labor Statistics, 2006). Student populations in graduate public service programs also reflect a greater degree of diversity. According to data provided by 138 member institutions of the National Association of Schools of Public Affairs and Administration (NASPAA), 16,038 students were enrolled in graduate programs in public administration, public policy, public affairs, and executive master's programs during the 20042005 academic year. Among the 5,459 master's degrees awarded, 57 percent were female and 43 percent were male, 57 percent were white, 17 percent were African American, 6 percent were Hispanic, 4 percent were Asian/Pacific Islander, and 1 percent were Native American (NASPAA, 2005). Evidence of a changing society and workforce creates an imperative to educate and prepare students to work in diverse organizations and communities. Cultural diversity has been ranked by public officials as an essential skill for government employees at all levels (Pitts and Wise, 2004). Recognizing the importance of cultural diversity, faculty members of public policy and administration programs have a responsibility to prepare students to work in diverse environments (Rice, 2004).

The expanded concept and definition of diversity incorporates the language of social equity (White, 2004). One step toward generating social equity in public policy and administration is to expose future leaders within the field to a variety of discourses from historically marginalized groups. Studies show that NASPAA, since the 1990s, has championed diversity in higher education by offering grants to institutions introducing diversity in their curricula (Pitts and Wise, 2004). Admittedly, most NASPAA member institutions as a body have embraced diversity and recognized the need for change; however, the burden or responsibility lies with the individual institutions to tackle diversity issues through their curricula. Section 4 of the National Association of Schools of Public Affairs and Administration (NASPAA) Standards for Professional Master's Degree Programs in Public Affairs, Policy, and Administration does not address diversity in the curriculum. Although diversity is listed as a core priority within NASPAA's strategic plan, the January 2006 edition of General Information and Standards for Professional Master's Degree Programs still excludes diversity as a common curriculum component. A NASPAA report in 2000 concluded that diversity courses were 
more likely to be seen or offered as electives and not required core courses. Where diversity courses are offered, they are integrated into existing courses rather than offered as stand-alone courses. A critical analysis of the 2000 NASPAA report shows that not enough effort has been made to teach diversity in the schools, although there are initiatives that promote diversity in the admissions process of students. Nevertheless, there is an effort to "[e]xplore moving from guidelines to standards with regard to MPA/MPP program diversity efforts and performance" (NASPAA, 2003).

The NASPAA 2009 Diversity Standard includes Diversity Across the Curriculum, which requires programs to incorporate diversity into the curriculum and other program activities. The standard also moves beyond race, gender, and ethnicity to include religion, disability, class, and sexual orientation. The proposed standard as it was originally written says, "Program activities must prepare students to work in and contribute to diverse workplaces and communities. Consequently, courses, curriculum materials, and other program activities should expose students to differences relating to social identity categories, such as race, ethnicity, gender, class, nationality, religion, sexual orientation, and disability" (NASPAA 2006).

This study examines attitudes toward the Diversity Across the Curriculum standard and explores what member institutions are doing to increase knowledge and awareness of the subject of diversity through curriculum and program activities. Specifically addressed are instructional strategies used to incorporate the subject of diversity into existing courses, the extent to which specialized courses in diversity are offered, and additional activities that occur outside of the classroom to expose students to a variety of diverse viewpoints. Perceptions of MPA/MPP directors on the Diversity Across the Curriculum standard are also considered.

\section{Teaching Diversity}

Continuous self-reflection and examination is one way for public policy and administration faculty to respond to diversity. We must continuously reexamine the substance, content, and strategy of our courses and teaching methods. A review of the literature on teaching diversity reveals that research has focused on two main areas. One area of research on teaching diversity that has received considerable attention is the extent to which stand-alone courses on diversity are offered. The second area of research focuses on how to integrate the subject of diversity into existing courses.

Studies on the extent to which stand-alone courses on diversity exist among graduate programs in public policy and administration have produced a variety of results. For example, one study by White (2004) found that six of the top 16 public policy and administration programs (as ranked by "Best Graduate Schools 2003") required a course on diversity in the core. However, three of the schools did not offer any courses on diversity. Other studies have demonstrated 
a limited number of courses offered on the subject of race (Gooden and Myers, 2004; White, 2004). Similarly, a study by Mills and Newman (2002) found that stand-alone courses on gender in public administration were offered by less than 30 percent of the respondents. Even more dismal is the absence of stand-alone courses on social class, religion, or sexual orientation, material that is nearly nonexistent in graduate public policy and administration programs (Oldfield, 2007; Rice, 2004). The extent to which elements of diversity are incorporated into existing courses also varies. According to a diversity report by NASPAA (2000), nearly half of the member institutions reported incorporating race, ethnicity, or gender into their existing courses; however, disability and sexual orientation received less attention.

Pedagogical techniques to integrate issues of diversity into existing courses have also received considerable attention in the literature. Cunningham and Wechsler (2002) maintain that teaching diversity issues in schools is important for practitioners but they noted that professors only teach "in their own academic preparation" (74). Nevertheless, common sense and research informs us that some courses are more conducive to the subject matter of diversity. For example, most human resource management (HRM) courses will address a wide variety of diversity issues such as racial and gender discrimination, sexual harassment (including recent court decisions related to sexual orientation), and religion. The nature of public law regulating the workplace makes HRM courses ideal for addressing issues of diversity. Similarly, issues of diversity may also be easily incorporated into public policy courses as examples to illustrate steps in the policy process. Other courses, such as budgeting or research methods, require a more concerted effort to integrate examples of diversity. Examples such as demographic trends or regressive tax structures may be incorporated; however, issues of diversity remain secondary. In comparison, Burnier (2003) integrates gender into an organization theory course, creating gender awareness, and introducing students to the work of feminine scholars. The use of learning contracts and internships has also been used by various faculty members within the field to address issues of diversity. Rubaii-Barrett (2006) advocates the use of learning contracts because it can be used to enhance the cultural competencies of a student, yet the "burden" of a faculty member to become an expert on diversity is minimized. Furthermore, contracts can be tailored to meet the needs of the student.

\section{Methods}

This study uses a mixed methods approach that incorporates questionnaire responses and content analysis. The list of NASPAA member institutions served as the sampling frame for both components of the research. The first component of the research utilizes a questionnaire developed to measure the extent to which diversity is incorporated into the curriculum and other program activities and perception of the Diversity Across the Curriculum standard. Although NASPAA's 
Standards 2009 on diversity also includes sections on student and faculty recruitment, this study focuses only on the section that addresses the MPA/MPP curriculum. The successful implementation of any initiative, including the Diversity Across the Curriculum standard, requires support from individuals who occupy positions of leadership; therefore, program directors were emailed invitations to complete an online survey. The second component of the research utilizes content analysis of course offerings at various member institutions. Fifty schools were selected from the NASPAA list of member institutions, excluding those who had completed the online survey.

\section{FINDINGS AND DisCUSSION}

\section{Survey}

Online survey invitations were distributed to 246 program directors, 92 of whom responded, resulting in a 38 percent response rate. Every respondent indicated that it was important (78 percent very important, 22 percent somewhat important) for graduate programs to promote awareness of cultural diversity issues. Nevertheless, course offerings on diversity have been somewhat limited. Not surprisingly, race, ethnicity, and gender are more likely to be addressed in stand-alone courses; a few of the course titles among the universities that responded included Civil Rights and Affirmative Action, Females and Minorities in Public Administration, Women and Men in the Workplace, Managing Intercultural Relations for Public and Nonprofit Agencies. Far fewer stand-alone courses address issues of religion, age, disability, or social class (see Table 1). Nevertheless, some courses appear to address a combination of diversity issues, evident in course titles such as Managing in a Multicultural Society, Race and Class in American Cities, and Politics of Poverty, Inequality, and Social Policy.

Table I. Diversity Content and Delivery

\begin{tabular}{|l|l|l|l|}
\hline Item & $\begin{array}{l}\text { Integrate subject } \\
\text { matter into } \\
\text { existing courses }\end{array}$ & $\begin{array}{l}\text { Subject matter is } \\
\text { addressed as a } \\
\text { stand-alone course }\end{array}$ & $\begin{array}{l}\text { Subject matter is } \\
\text { not addressed }\end{array}$ \\
\hline Age & $82.2 \%$ & $6.7 \%$ & $11.1 \%$ \\
\hline Disability & $89.5 \%$ & $7 \%$ & $3.5 \%$ \\
\hline Ethnicity & $75.6 \%$ & $17 . \%$ & $6.7 \%$ \\
\hline Gender & $81.8 \%$ & $17 \%$ & $1.1 \%$ \\
\hline Race & $76.9 \%$ & $20.9 \%$ & $2.2 \%$ \\
\hline Religion & $60 \%$ & $5.9 \%$ & $34.1 \%$ \\
\hline Social Class & $72.7 \%$ & $11.4 \%$ & $15.9 \%$ \\
\hline
\end{tabular}


The majority of respondents (68 percent) also have no intention of increasing the number of stand-alone courses that address diversity issues. However, many respondents indicate that issues of diversity are often integrated into existing courses through a variety of instructional strategies (see Table 2). One responded stated, "Different pedagogical approaches are warranted depending on the composition of the student body and the population they serve." Another respondent reported the use of collaborative projects that allow students to work with peers who are "different from themselves." Many programs have also used social gatherings (73 percent), speaker series (61 percent), and workshops (36.7 percent) to expose students to diverse viewpoints outside of the classroom. One university also reported the use of an "improvisational troupe to reflect on and share personal narratives about race" at the program orientation.

Most program directors also believe that their graduates are prepared to work in a culturally diverse organization, 48 percent reported that graduates were strongly prepared and 50 percent reported that graduates were somewhat prepared. The response was similar when the program directors were asked if graduates were prepared to serve a culturally diverse citizenry ( 49 percent answered strongly prepared, 49 percent somewhat prepared). One respondent stated, "I think the emphasis should be on managing in diverse environments, creating and analyzing policy that effectively addresses the needs of diverse citizenries and interacting in a professional context with diverse peers."

The survey also included a copy of NASPAA's statement of the proposed Diversity Across the Curriculum standard. Most program directors (56 percent) responded that the standard as it is worded offers flexibility in the implementation initiatives among member institutions, 37 percent reported that the standard is somewhat flexible, and 7 percent reported that the standard is not at all flexible. The majority of directors (73 percent) also stated that their graduate program currently satisfies the proposed standard; 19 percent were uncertain, and 7 percent reported that their program did not satisfy the proposed standard. Nevertheless, 53 percent of the directors reported that some faculty members will need to revise their instructional strategies to meet the standard.

Table 2. Instructional Strategies to Incorporate Diversity into Existing Courses

\begin{tabular}{|l|l|}
\hline Instructional Strategies & $\begin{array}{l}\text { Percentage of Respondents } \\
\text { Using Strategy }\end{array}$ \\
\hline Required readings & $91 \%$ \\
\hline Case studies or simulations & $71 \%$ \\
\hline Guest lectures & $65 \%$ \\
\hline Written assignments & $56 \%$ \\
\hline Audio-visual presentations & $27 \%$ \\
\hline
\end{tabular}


The survey also included a section for respondents to provide written comments about the proposed Diversity Across the Curriculum standard. One director noted that the standard should not become a "litmus test of program legitimacy." Another director was concerned about lack of clarity:

It is unclear to me from the statement whether "courses, curriculum and program activities" means all such features of a program must comply with this standard or whether a preponderance of such features, a small set of such features that is strategically aimed at achieving the overarching objective, or that such features are demonstrably present in some way. I think for clarity of implementation it would be good if the standard gave some hint about what is intended with respect to the breadth of this standard.

Similar concerns about a lack of clarity or measurable objectives were also asserted by a director who said, "It would be very nice to have the results of a pilot study (or series of pilot studies) showing member institutions exactly what is to be accomplished."

Although a few directors raised concerns about lack of clarity, flexibility was the major theme that emerged from the written comments; many respondents noted variations in diversity across campuses and variations in resources available to implement any initiatives. One director stated, “The final standard should allow programs flexibility in incorporating diversity into curricula in order to reflect varying institutional missions, cultures, and philosophies." Several respondents indicated that their campuses and programs exhibit a high degree of diversity in both student and faculty composition. Others noted the difficulty in attracting and retaining diverse faculty. For example, one director stated,

There needs to be the realization that diversity means different things to different programs. Some programs have a much easier time meeting the standards than others. For instance, racial diversity is more difficult in regional universities existing in regions that are not racially diverse. Some programs must struggle much more than others to recruit a diverse faculty as well. Thus, the standard needs as much flexibility as possible and those judging the standard need to recognize that the universities and programs themselves are very diverse.

Several respondents also asserted the need for flexibility because of variations in resources across programs. One director noted that a small faculty size results in workload constraints and makes it difficult to develop and implement standalone courses. The respondent asserted that directors of small programs can emphasize to the faculty the importance of integrating diversity within existing 
courses. Another director indicated that their current core of seven courses meets NASPAA standards and that "additional expectations would invariably mean a trade-off in other areas."

\section{Content Analysis}

In addition to the online survey, a content analysis of course offerings was conducted. Fifty schools were selected from the NASPAA list of member institutions, excluding those who had completed the online survey. University Web sites were used to acquire program requirements and course descriptions. Of interest are the numbers of member institutions in the content analysis sample that offer stand-alone courses on diversity. Key terms included age, disability, gender, race/ethnicity, nationality, religion, sexual orientation, and social class. Among the 50 member institutions in the content analysis sample, 15 provided stand-alone courses incorporating some element of diversity (see Table 3). None of the stand-alone courses on diversity are included in the core; however, several member institutions do offer concentrations in areas relevant to diversity. One institution offers a stand-alone course that specifically addresses most, if not all, of the individual elements of diversity in the workplace, aptly titled Managing Diversity in the Workplace. Two institutions in the content analysis sample offer stand-alone courses that address race/ethnicity through such course titles as Racial Inequality in Public Policy and Strategies of Equality. In comparison, gender as a component of diversity varies from concentrations within programs to being integrated into diversity courses. Two member institutions within the content analysis sample offer concentrations in women and public policy. Two institutions offer stand-alone courses on gender as it relates to public policy and administration under course titles such as Women and Leadership and Survey of Women, Law, and Public Policy. Others combine components of diversity such as nationality and gender, for example, to offer courses such as Globalization and Gender. Only one member institution in the content analysis sample offers a stand-alone course-Poverty, Inequality, and Public Policy — that addresses social class. Similarly, only one member institution offers a course on age and disability, aptly titled Aging and Disability Policy. Not surprisingly, stand-alone courses on religion or sexual orientation are not offered within the graduate programs in public affairs and administration at any of the institutions in the content-analysis sample. In stark contrast, 11 of the 15 institutions offered stand-alone courses that address nationality as a component of diversity. This study utilizes the definition of nationality offered by Hewins-Maroney and Williams (2007) as "courses exploring issues associated with administering public programs to non-native American populations in the United States" (34). Concentrations in international development, international administration, and global public policy are offered at six of the member institutions in our sample. Five additional institutions offer courses on international public administration and governance through various 
course titles including Comparative Public Administration, International Perspectives on Public Administration, Comparative Public Policy and Administration, and Policy Evaluation in Developing Countries.

Among the 50 member institutions in the content analysis sample (excludes online survey respondents), 15 graduate programs offered stand-alone courses on issues of diversity.

The results of this content analysis indicate that stand-alone courses on issues of diversity are still an exception rather than the norm among graduate programs in public affairs and administration. It also appears that MPA/MPP programs are moving in a direction that emphasizes diversity from a global perspective. The variations in the number and types of stand-alone courses on diversity also indicate a wide range of program resources in terms of both structure and resources. For example, MPA/MPP programs housed in political science departments with either additional MA or $\mathrm{PhD}$ programs find it easier to offer stand-alone courses on diversity than programs operating only an MPA/MPP program. Furthermore, larger programs benefit from higher student enrollment in individual courses and more faculty members to spread out the workload, making it easier to justify stand-alone courses on diversity. The results of this content analysis also illustrate the potential flexibility of meeting broad standards of diversity and the difficulty

Table 3. Diversity Content Addressed in Stand-alone Courses

\begin{tabular}{|l|l|l|l|l|l|l|l|l|}
\hline Schools & Age & Disability & Gender & $\begin{array}{l}\text { Race/ } \\
\text { Ethnicity }\end{array}$ & Nationality & Religion & $\begin{array}{l}\text { Sexual } \\
\text { Orientation }\end{array}$ & $\begin{array}{l}\text { Social } \\
\text { Class }\end{array}$ \\
\hline A & 0 & 0 & 0 & 0 & I & 0 & 0 & 0 \\
\hline B & 0 & 0 & 0 & 0 & 0 & 0 & 0 & 0 \\
\hline C & 0 & 0 & 0 & 0 & I & I & 0 & 0 \\
\hline D & 0 & 0 & 0 & 0 & I & 0 & 0 & 0 \\
\hline E & 0 & 0 & 0 & 0 & I & 0 & 0 & 0 \\
\hline F & 0 & 0 & 0 & 0 & I & 0 & 0 & 0 \\
\hline G & I & I & I & I & I & 0 & 0 & 0 \\
\hline H & 0 & 0 & 0 & 0 & I & 0 & 0 & 0 \\
\hline I & 0 & 0 & I & 0 & I & 0 & 0 & 0 \\
\hline J & 0 & 0 & I & 0 & I & 0 & 0 & 0 \\
\hline K & 0 & 0 & I & I & I & 0 & 0 & 0 \\
\hline L & I & 0 & I & I & 0 & 0 & 0 & I \\
\hline M & 0 & 0 & I & 0 & I & 0 & 0 & 0 \\
\hline N & 0 & 0 & 0 & 0 & 0 & 0 & 0 & 0 \\
\hline O & 0 & 0 & 0 & 0 & I & 0 & 0 & 0 \\
\hline
\end{tabular}


in classifying any one particular course. For example, social class, like the other elements of diversity such as ethnicity or religion, might be inherent in global public policy courses. Of course, it might also be excluded as a specific topic of discussion from the very same courses. It is imperative, therefore, that instructors of such courses articulate how components of diversity are specifically addressed in their courses.

Readers should interpret the results of both the online survey and the content analysis conservatively as there are limitations in the current study. A reasonable response rate for mail surveys averages between 20 percent and 40 percent with a follow-up (Frankfort-Nachmias and Nachmias, 2000); however, an average follow-up rate has not been established for online surveys. In addition, selfreporting may overestimate the degree to which diversity issues are integrated into existing courses. The results of the content analysis are also limited to course titles and descriptions. Although the content analysis captures information on diversity in the curriculum of 50 additional member institutions that did not respond to the survey, the results of the content analysis cannot be generalized to all member institutions.

\section{CONCLUSION}

The results of the survey and content analysis support previous studies that have demonstrated a limited number of stand-alone courses on diversity among public administration and policy programs. The instructional strategies reported might also be helpful to faculty members seeking to integrate diversity into existing courses. Furthermore, the perceptions of program directors on the Diversity Across the Curriculum standard reinforce the importance of clarity and flexibility.

A few recommendations for achieving diversity across the curriculum are offered. First, NASPAA, member institutions, program directors, and faculty members should continue to emphasize the necessity of cultural competencies in the workplace. Students must not only be able to function effectively in diverse organizations, they should understand the communities they serve. Second, a balance must be maintained between NASPAA and member institutions. Universities should consider incorporating diversity courses into the core curriculum. Nevertheless, budgetary and human resource constraints are recognized. NASPAA should remain flexible enough to recognize program variations; however, member institutions should also demonstrate genuine effort to move in an established strategic direction that recognizes the importance of diversity. If it is not feasible to offer stand-alone courses on diversity, faculty members should consider integrating elements of diversity into their existing courses. Unfortunately, the lack of diversity among students or faculty is often used as a blanket defense for lack of coverage of diversity issues in the curriculum. The very fact that diversity is limited in such programs and/or regions demonstrates a greater need to raise awareness of issues beyond one's province. Ironically, extreme diver- 
sity has also been used as a blanket defense for lack of coverage of diversity issues in the curriculum. One assumption is that diverse students share and express different viewpoints in the classroom and work together as groups, when often students self-segregate. A second assumption is that students have a heightened awareness of the implications of their own identities (e.g., gender awareness) before they enter the classroom, when often such awareness emerges through the educational experience. Member institutions should continue to embrace efforts to recruit faculty and students from diverse backgrounds and NASPAA should recognize variations across programs; however, a lack of diversity or extreme diversity should not be used as a justification for excluding issues of diversity in the curriculum. We all share responsibility in preparing future leaders in the field of public policy and administration.

\section{Note}

1. At the Annual Business Meeting (October 12, 2007), NASPAA voted to approve the proposed Diversity Across the Curriculum Standard. Age and Veteran Status was also incorporated as components of diversity.

\section{REFERENCES}

Burnier, DeLysa. 2003. "Giving Voice to Gender in the MPA Classroom: Teaching Organization Theory with a Gender Emphasis.” Journal of Public Affairs Education, 9(4):275-283.

Cunningham, Robert B., and Louis Weschler. 2002. “Theory and the Public Administration Student/ Practitioner." Public Administration Review 62(1):104-111.

Frankfort-Nachmias, Chava, and David Nachmias. 2000. Research Methods in the Social Sciences, $6^{\text {th }}$ ed. New York: Worth Publishers.

Gooden, Susan, and Samuel Myers, Jr. 2004. "Teaching Social Equity in the MPA: Reflections from the Social Equity Symposium.” Journal of Public Affairs Education, 10(2):155-175.

Gribbin, August, and Robert Stacy McCain. 1999. "Polls Dance to Latin Beat —Includes Article on Minorities in America." Insight on the News, Nov 15. Available at http://findarticles.com/p/articles/ mi_m1571/is_42_15/ai_57770436. Accessed October 8, 2007.

Hewins-Maroney, Barbara, and Ethel Williams. 2007. "Teaching Diversity in Public Administration: A Missing Component?” Journal of Public Affairs Education, 13(1):29-40.

Mills, J., and M. Newman. 2002. "What Are We Teaching about Gender Issues in Public Affairs Courses?" Journal of Public Affairs Education, 8(2):25-43.

Myers, Jr. Samuel. 2004. "Teaching Social Equity in the MPA: Reflections from the Social Equity Symposium." Journal of Public Affairs Education, 2:155-175.

National Association of Schools of Public Affairs and Administration. 2000. "NASPAA 2000 Diversity Report." Washington, D.C.

National Association of Schools of Public Affairs and Administration. 2003. "Strategic Directions." Available at http://www.naspaa.org/principals/strategicplanning/future_directions2004.asp. Accessed September 22, 2007.

National Association of Schools of Public Affairs and Administration. 2005. "Enrollment and Degrees Awarded Data: Master's Degrees 2004-2005.” Available at http://www.naspaa.org/principals/ almanac/Survey2005/mastersdegrees.asp\#ENROLLMENT. Accessed September 17, 2007.

National Association of Schools of Public Affairs and Administration. 2007. "Proposed NASPAA Diversity Standard.” Available at http://www.naspaa.org/accreditation/diversity_standard/main.asp. Accessed April 11, 2007.

National Association of Schools of Public Affairs and Administration. 2006. "Commission on Peer Review and Accreditation. General Information and Standards for Professional Master's Degree 
Programs. Available at http://www.naspaa.org. Accessed May 20, 2007.

Oldfield, Kenneth. 2007. "How Can We Democratize Higher Education if We Don't Count the Votes?" Journal of Public Affairs Education, 13(1):133-146.

Pitts, David W., and Lois R. Wise. 2004. "Diversity in Professional Schools: A Case Study of Public Affairs and Law." Journal of Public Affairs Education, 10(2):125-142.

Rice, Mitchell. 2004. "Organizational Culture, Social Equity, and Diversity: Teaching Public Administration Education in the Postmodern Era." Journal of Public Affairs Education, 10(2):143154.

Rubaii-Barrett, Nadia. 2006. "Teaching Courses on Managing Diversity: Using Learning Contracts to Address Challenges and Model Behavior." Journal of Public Affairs Education, 12(3):361-383.

U.S. Department of Labor, Bureau of Labor Statistics. 2005. "Women in the Labor Force: A Databook." Available at http://www.bls.gov/cps/wlf-databook2005htm. Accessed October 9, 2007.

U.S. Department of Labor, Bureau of Labor Statistics. 2006. "Charting the U.S. Labor Market in 2006." Available at http://www.bls.gov/cps/labor2006/home.htm. Accessed October 9, 2007.

White, Susan. 2004. "Multicultural MPA Curriculum: Are We Preparing Culturally Competent Administrators?" Journal of Public Affairs Education, 10(2):111-123.

Heather Wyatt-Nichol is an assistant professor at Stephen F. Austin State University in Nacogdoches, Texas. She has taught courses in human resources, program evaluation, and ethics and currently teaches public administration and public organizations and management. Her research interests include organizational behavior, organizational justice, social equity, and ethical climates. She may be reached at wyatthl@sfasu.edu.

Kwame Badu Antwi-Boasiako is an assistant professor in the MPA program at Stephen F. Austin State University in Nacogdoches, Texas. He teaches classes focusing on policy and program evaluation in the MPA program. He also teaches public policy and introduction to American government including international relations. His primary fields of interest include traditional institution and democracy in Africa, teaching public administration, terrorism, and diversity in the public sector. His current research involves diversity in school curricula and hiring in the public sector. He may be reached at antwibokb@sfasu.edu. 